\title{
Review Article \\ Inflammation and Immune Response in COPD: Where Do We Stand?
}

\author{
Nikoletta Rovina, Antonia Koutsoukou, and Nikolaos G. Koulouris \\ Intensive Care Unit, 1st Department of Respiratory Medicine, Medical School, National and Kapodistrian University of Athens and \\ "Sotiria" Chest Disease Hospital, 152 Mesogeion Avenue, 11527 Athens, Greece \\ Correspondence should be addressed to Nikoletta Rovina; nikrovina@med.uoa.gr
}

Received 12 February 2013; Accepted 2 July 2013

Academic Editor: Helen C. Steel

Copyright (C) 2013 Nikoletta Rovina et al. This is an open access article distributed under the Creative Commons Attribution License, which permits unrestricted use, distribution, and reproduction in any medium, provided the original work is properly cited.

Increasing evidence indicates that chronic inflammatory and immune responses play key roles in the development and progression of COPD. Recent data provide evidence for a role in the NLRP3 inflammasome in the airway inflammation observed in COPD. Cigarette smoke activates innate immune cells by triggering pattern recognition receptors (PRRs) to release "danger signal". These signals act as ligands to Toll-like receptors (TLRs), triggering the production of cytokines and inducing innate inflammation. In smokers who develop COPD there appears to be a specific pattern of inflammation in the airways and parenchyma as a result of both innate and adaptive immune responses, with the predominance of CD8+ and CD4+ cells, and in the more severe disease, with the presence of lymphoid follicles containing B lymphocytes and T cells. Furthermore, viral and bacterial infections interfere with the chronic inflammation seen in stable COPD and exacerbations via pathogen-associated molecular patterns (PAMPs). Finally, autoimmunity is another novel aspect that may play a critical role in the pathogenesis of COPD. This review is un update of the currently discussed roles of inflammatory and immune responses in the pathogenesis of COPD.

\section{Introduction}

Chronic obstructive pulmonary disease (COPD) is an inflammatory disease of the airways, mainly associated with cigarette smoke (CS) exposure. The disease is characterised by a progressive and irreversible decline in lung function caused by airflow obstruction, destruction of parenchyma, and emphysema $[1,2]$.

The pathophysiological changes seen in COPD have been well characterised and are used to diagnose patients. Exposure to inhaled pollutants, primarily cigarette smoke (CS), is thought to lead to the chronic airway inflammation seen in COPD via the activation of structural and inflammatory cells within the lung (epithelial cells and alveolar macrophages). These in turn release chemotactic mediators which recruit additional inflammatory cells (CD8+ T cells, neutrophils, monocytes, and lymphocytes) into the lung perpetuating a state of chronic inflammation, which is thought to cause the structural changes in the airway, airway obstruction, and respiratory symptoms [3]. Interestingly, only $15-20 \%$ of smokers develop COPD, suggesting that genetic predisposition and environmental factors play a role in the pathogenesis of the disease. Additionally, the chronic inflammation persists despite smoking cessation $[4,5]$. This has led to the concept that an abnormal inflammatory response to CS leads to the development of COPD in the susceptible individual.

Although much progress has been made in the diagnosis and management of the disease, understanding the features of the underlying mechanisms leading to the pathogenesis of COPD still remains to be determined. It has been proposed that other mechanisms beyond chronic inflammation are implicated in the development and the progression of the disease, such as cellular senescence and apoptosis [6-9]. Recent studies in murine models with COPD suggest a potential role of adaptive immunity [10-12], while there is also evidence for an association of COPD with autoimmune responses [13].

\section{Inflammatory Responses in COPD}

Several inflammatory cells and their mediators participate in the inflammatory response in COPD. Exposure to cigarette 
smoke, noxious particles, or gases can activate an inflammatory cascade in the airways resulting in the production of a number of potent cytokines and chemokines which play a critical role in the induction of chronic inflammation and subsequent tissue destruction [14]. Epithelial cells are activated to produce inflammatory mediators, including tumour necrosis factor (TNF-) a, interleukin (IL-) $1 b$, granulocyte-macrophage colony-stimulating factor (GMCSF), and CXCL8 (IL-8) [14, 15]. Furthermore, epithelial cells in small airways may be an important source of transforming growth factor (TGF-) b, which then induces local fibrosis [14]. Comer et al. [16] showed that cigarette smoke extract (CSE) pretreatment of primary bronchial epithelial cells (PBECs) followed by $P$. aeruginosa LPS stimulation reduced IL-8 release from COPD PBECs but increased it from cells of smokers without airflow obstruction and nonsmokers. TLR-4 expression, MAPK, and NF- $\kappa \mathrm{B}$ activation in COPD cultures were reduced after CSE treatment, but not in the smokers without airflow obstruction or nonsmoking groups, which was associated with increased apoptosis.

Increased numbers of activated neutrophils are found in sputum and bronchoalveolar lavage and airway smooth muscle of patients with COPD [17] yet increase relatively little in the airways or lung parenchyma. This may reflect their rapid transit through the airways and parenchyma. The proportion of neutrophil accumulation correlates to the disease severity [18]. There are several chemotactic signals that have the potential for neutrophil recruitment in COPD, including LTB4, IL-8, and related CXC chemokines, including CXCL1 and CXCL8, GRO-a (growth-related oncogene-a), and ENA-78 (epithelial neutrophil-activating protein of $78 \mathrm{kDa}$ ) which are increased in COPD airways [19]. These mediators may be derived from alveolar macrophages and epithelial cells, but the neutrophil itself may be a major source of IL-8 [19]. Neutrophil recruitment to the airways and parenchyma involves adhesion to endothelial cells and E-selectin is upregulated on endothelial cells in the airways of COPD patients [20]. Adherent neutrophils then migrate into the respiratory tract under the direction of neutrophil chemotactic factors, which include interleukin (IL-) 8 and leukotriene B4 (LTB4). Neutrophil survival in the respiratory tract may be increased by cytokines, such as granulocyte-macrophage colony-stimulating factor (GM-CSF) and granulocyte colony-stimulating factor (G-CSF). Neutrophils secrete serine proteases, including neutrophil elastase (NE), cathepsin G, and proteinase-3, as well as matrix metalloproteinase (MMP)-8 and MMP-9, which may contribute to alveolar destruction. These serine proteases are also potent mucus stimulants [14].

Macrophages appear to play a pivotal role in the pathophysiology of COPD and can account for most of the known features of the disease [21]. There is a marked increase (510 -fold) in the numbers of macrophages in airways, lung parenchyma, BAL fluid, and sputum in patients with COPD. Furthermore, macrophages are localised to sites of alveolar wall destruction in patients with emphysema [22]. There is a correlation between macrophage numbers in the airways and the severity of COPD [23].
Macrophages may be activated by cigarette smoke extract to release inflammatory mediators, including tumour necrosis factor (TNF-) a, IL-8, other CXC chemokines, monocyte chemotactic peptide (MCP)-1, LTB4, and reactive oxygen species providing a cellular mechanism that links smoking with inflammation in COPD. Alveolar macrophages also secrete elastolytic enzymes, including MMP-2, MMP-9, MMP-12, cathepsins K, L, and S, and neutrophil elastase taken up from neutrophils [24, 25]. Most of the inflammatory proteins that are upregulated in COPD macrophages are regulated by nuclear factor $\kappa \mathrm{B}(\mathrm{NF}-\kappa \mathrm{B})$ which is activated in alveolar macrophages of COPD patients, particularly during exacerbations $[26,27]$.

The increased numbers of macrophages in smokers and COPD patients may be due to increased recruitment of monocytes from the circulation in response to monocyte selective chemokines. Macrophages also have the capacity to release the chemokines interferon-c inducible protein (IP10), interferon-inducible T-cell chemoattractant (I-TAC), and monokine-induced by interferon-c (Mig), which are chemotactic for $\mathrm{CD} 8 \mathrm{z} \mathrm{Tcl}$ cells via interaction with the CXCR3 receptor expressed on these cells [28]. The increased numbers of macrophages in COPD may be due to increased recruitment of monocytes but may also due to increased proliferation and prolonged survival in the lungs.

\section{Innate Immune Responses in COPD: The Role of Inflammasome}

The innate immune system is the first line of defence against microbial infections. Several humoral factors and cells (neutrophils, macrophages, dendritic cells, natural killer cells, monocytes, and mast cells) that participate in innate immunity are recruited in order to control pathogen invasion. Recently, there has been growing evidence to implicate the NLRP3 inflammasome and its products in the inflammation observed in COPD patients [29, 30]. The NLRP3 inflammasome is a multimeric protein complex important in stimulating caspase- 1 activation and subsequently the release of the mature form of the inflammatory cytokines IL- $1 \beta$ and IL-18 [29]. (Figure 1) The primary role of the inflammasome and its products, as part of the innate immune system, is that they can be triggered to assist in defence against invading pathogens. Invading pathogens drive an increase in reactive oxygen species (ROS) leading to the activation of the inflammasome, both directly and indirectly [31] to produce inflammasome-associated procytokines, after their recognition by a family of receptors through pathogen-associated molecular patterns (PAMPs) [32]. This recognition is achieved by several families of pattern recognition receptors (PRRs) expressed in alveolar macrophages, dendritic cells, and epithelial cells, which first contact microbial pathogens. The PRRs include Toll-like receptors (TLRs), nucleotidebinding domain leucine-rich repeat-containing receptors (NLRs), C-type lectin receptors (CLRs), and RIG-I-like receptors (RLRs) [33]. TLRs are known to recognize PAMPs on the cell surface, whereas NLRs sense microbial molecules in the cytosol of the host cell [34]. A number of groups have 


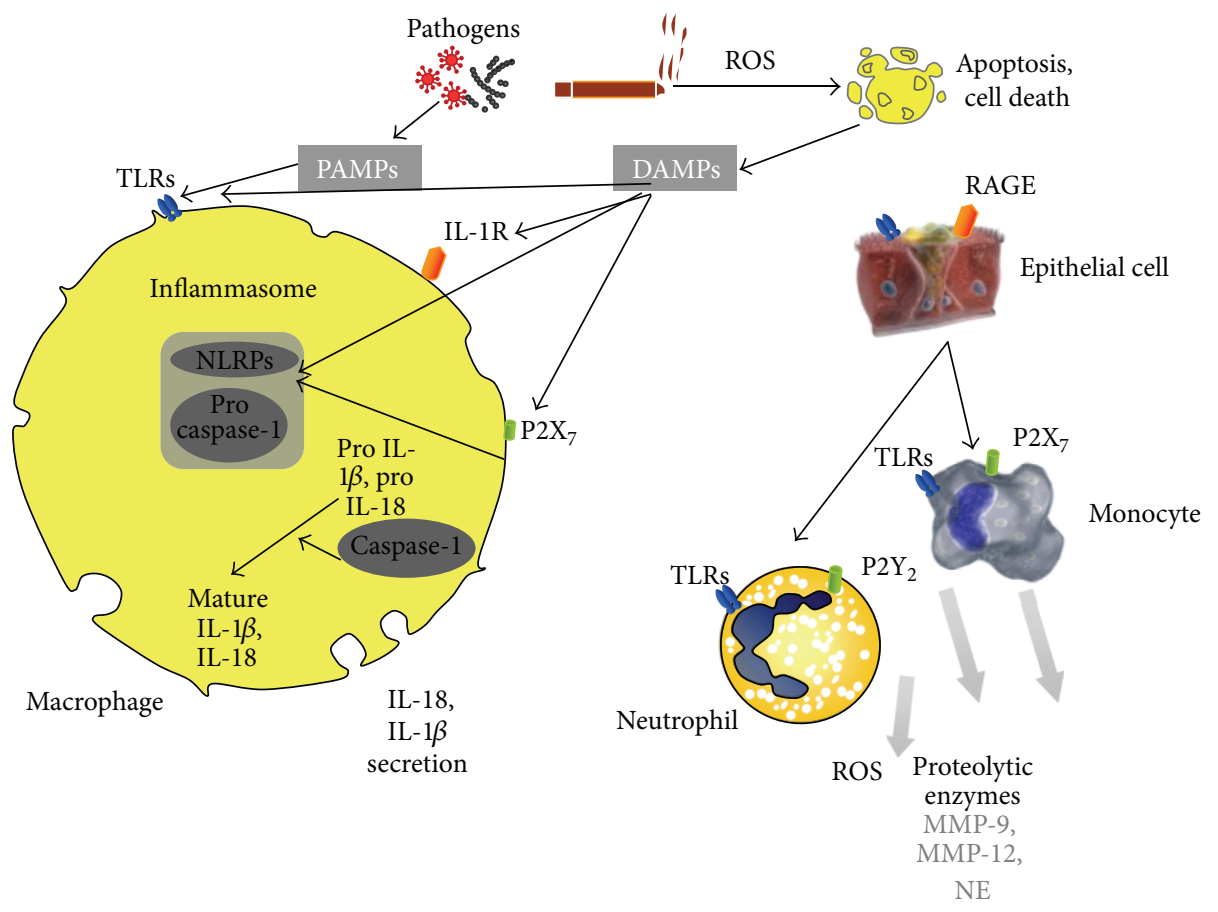

FIGURE 1: Inflammasome-associated inflammation in COPD.

shown that the TLR4 is central to the inflammatory response in murine models of COPD [35-37]. Mice that have been genetically altered so that the TLR4 is not functional fail to develop the inflammation after cigarette smoke challenge that is observed in wild-type mice. Activation of the TLR4 alone, in vitro at least, is not thought to lead to marked activation of the inflammasome. In lung tissues collected from clinically indicated resections it was demonstrated that the percentage of CD8+ T cells expressing TLR1, TLR2, TLR4, TLR6, and TLR2/1 were significantly increased in COPD subjects relative to those without COPD. In contrast, from the same subjects, only TLR2/1 and TLR2 on lung CD4+ T cells and CD8+ NKT cells, respectively, showed a significant increase in COPD and there was no difference in TLR expression on lung CD56+ NK cells. Production of the Tcl cytokines IFN- $\gamma$ and TNF- $\alpha$ by lung CD8+ T cells was significantly increased via costimulation by Pam3CSK4, a specific TLR2/1 ligand, but not by other agonists. Furthermore, this increase in cytokine production was specific to lung CD8+ $\mathrm{T}$ cells from patients with COPD as compared to lung CD8+ T cells from smokers without COPD. These data suggest that as lung function worsens in COPD, the autoaggressive behavior of lung CD8+ T cells could increase in response to microbial TLR ligands, specifically ligands against TLR2/1 [37].

The innate immune system also contains PRRs that recognize danger signals produced by cells in response to pathogenic conditions. These danger signals or dangerassociated molecular patterns (DAMPs) are released in conditions of cellular damage or stress or formed by pathogenmediated modification of host proteins and can be recognized by the PRRs of the innate immune system. Some DAMPs also have the ability to activate TLRs. Activation of both PAMPs and DAMPs together leads to enhanced release of the mature forms of the inflammatory cytokines.

The NLRP3 inflammasome can be activated by a number of ways; one of which is through ATP acting on the P2X7 receptor [38-44]. Increases in ATP levels have been reported in in vitro/in vivo models of COPD $[45,46]$ and in clinical samples [47, 48]. This increase in ATP levels has been suggested to play a role in the chemotaxis and activation of inflammatory cells, such as neutrophils, through P2Y receptors $[48,49]$.

HMGB1 is an abundant chromatin protein that acts as a cytokine when released in the extracellular milieu by necrotic and inflammatory cells [50]. Extracellular HMGB1 can be regarded as a signal of tissue injury and a mediator of inflammation [51]. HMGB1 mRNA and protein expressions were identified to be positively correlated with $\mathrm{NF} \kappa \mathrm{B}$ protein expression in a rat model of chronic obstructive pulmonary disease [52]. The expression of receptor for advanced glycation end products (RAGE), which bind HMGB1, was also raised in airway epithelium [53]. Deficiencies in soluble forms of RAGE (sRAGE) are linked to heightened inflammation in various chronic conditions. Very recently, Sukkar et al. [54] demonstrated that COPD patients had undetectable levels of lung sRAGE, while levels of lung sRAGE in asthma/ COPD patients without neutrophilia were similar to those in controls. Systemic sRAGE was significantly decreased in subjects with neutrophilic asthma or COPD compared with those without airway neutrophilia. Ferhani et al. [50] recently reported elevated levels of high-mobility group box 1 (HMGB1) in the bronchoalveolar lavage of patients with 
COPD, while Hou et al. [51] reported significantly higher levels of HMGB1 in induced sputum of COPD patients compared to those of asthma patients and healthy controls. Kanazawa et al. [55] showed that HMGB1 levels in peripheral airways were elevated in smokers without COPD, as compared with nonsmokers, and those levels were further augmented in COPD patients. Those levels were associated with the severity of COPD. These data support a potential role for HMGB1 as a biomarker and diagnostic tool for the differential diagnosis COPD.

Activation of PRRs such as TLRs and RAGE leads to increased expression of prointerleukin $1 \beta$ which is subsequently cleaved into mature interleukin $1 \beta$ by NLRP inflammasomes. In the inflammatory milieu present in the lungs of human patients with COPD and animals exposed to cigarette smoke, are increased levels of cytokines linked to the activation of the NLRP3 inflammasome, that is, IL-1 $\beta$ and IL$18[30,56]$. Furthermore, there is some evidence to suggest that these cytokines are central to the inflammation seen in models of COPD [57-59].

Increased IL- $1 \beta$ levels have been reported after cigarette smoke challenge, which correlate with increases in caspase activity, IL-1 $\beta$, and neutrophils $[57,60]$. In the study of Singh et al. it was demonstrated that serum IL-1 $\beta$ levels were negatively correlated with FEV1 in COPD patients $[61,62]$. In murine model studies it was shown that mice overexpressing IL-1 $\beta$ in lung epithelium display a COPD-like phenotype consisting of lung inflammation, emphysema, and airway fibrosis [63]. In contrast, mice lacking IL-1 receptor type 1 (IL1R) exhibited a significant decrease in airway neutrophilia in response to cigarette smoke [36,57]. Recent data further document the implication of IL-1 $\alpha$ as central to the initiation of smoke-induced neutrophilic inflammation $[64,65]$. Botelho et al. [64] showed that although a strong correlation between IL-1 $\alpha$ and $\beta$ levels was seen in smoke-exposed gene-deficient mice during stable disease and periods of exacerbation, neutrophilic inflammation was IL- $1 \alpha$ dependent and IL- $1 \beta$ and caspase-1 independent. These data suggest that IL-1 $\alpha /$ IL-1R1targeted therapies may be relevant for limiting inflammation and exacerbations in COPD. In their most recent work, Botelho et al. [65] showed that acute and chronic cigarette smoke exposure led to increased accumulation and activation of dendritic cells, which was IL-1R1/IL-1alpha dependent, but TLR4 and IL-1beta independent. Finally, Pauwels et al. [66] showed that in cigarette smoke-exposed mice (wildtype mice treated with anti-IL- $1 \alpha$ or anti-IL- $1 \beta$ antibodies, IL-1RI knockout (KO), Nlrp3 KO, and caspase-1 KO mice) pulmonary inflammation was dependent on IL-1RI and could be significantly attenuated by neutralising IL-1 $\alpha$ or IL- $1 \beta$. In human subjects, IL- $1 \alpha$ and IL-1 $\beta$ were significantly increased in total lung tissue and induced sputum of patients with COPD, respectively, compared with never-smokers.

Elevated IL-18 levels have also been found in COPD patients [67]. Significantly increased levels of IL-18 have been demonstrated in sputum supernatants and peripheral blood of COPD patients compared to healthy smokers and nonsmokers, suggesting that IL-18 may be implicated in the pathogenesis of COPD [68-71]. There is evidence that
IL-18 is implicated in the pathogenesis of COPD. It has been shown that the expression of IL-18 in the mature murine lung induces inflammation that is associated with the accumulation of CD4(+), CD8(+), CD19(+), and NK1.1(+) cells; emphysema; mucus metaplasia; airway fibrosis; vascular remodeling; and right ventricle cardiac hypertrophy [72]. In the study of Kang et al. [72] it was demonstrated that IL18 induces type 1 , type 2 , and type 17 cytokines with IFN- $\gamma$ inhibiting macrophage, lymphocyte, and eosinophil accumulation while stimulating alveolar destruction and genes associated with cell cytotoxicity and IL-13 and IL-17A inducing mucus metaplasia, airway fibrosis, and vascular remodeling. Wang et al. [73] showed that he proportions of IL-18R $\alpha$ expressing T lymphocytes and CD8(+) T lymphocytes were significantly higher in stable COPD patients than in nonsmokers and current smokers. In the study of Kratzer et al. [74] chronic exposure of the Sprague-Dawley rats to secondhand smoke resulted in emphysematous lesions accompanied by a decreased expression of the natural inhibitor of IL18, namely, IL-18-binding protein. Moreover, IL-18 down regulated the expression of VEGF receptor-1 and VEGFR receptor-2 and induced apoptosis in pulmonary microvascular endothelial cells in vitro. Kang et al. [58] have shown that IL-18 knockout mice show significantly decreased inflammation and emphysema compared to wild-type mice following CS exposure while Hoshino et al. [75] showed that mice overexpressing IL-18 in the lung display a COPD-like phenotype. These data support the active role of the inflammasome in the inflammation observed after exposure to CS.

\section{Adaptive Immune Responses in COPD}

4.1. T Cells. Cigarette smoke-driven antigens, bacterial or viral agents, breakdown products from extracellular matrix, and possibly lung tissue autoantigens can elicit adaptive immune responses in the lungs of COPD patients, with the participation of cytotoxic CD8+ T cells, T helper 1 and Th17 CD4+ cells $[76,77]$, and B-cell responses with antibody production [78]. The number of pulmonary $\mathrm{CD} 8+\mathrm{T}$ cells increases substantially with higher stages of airflow limitation and emphysema [77]. On activation, CD8+ T cells release proteolytic enzymes such as perforin and granzymes, which cause cell death of structural cells by apoptosis or necrosis [76, 78, 79]. Recently, Kim et al. [80] demonstrated that upregulation of granzyme B in CD8(+) and non-CD8(+) cells is an early phenomenon of small airway wall remodelling in centrilobular emphysema, suggesting a possible role in the pathogenesis of COPD. Finally, Hodge et al. [81] demonstrated that in the blood of COPD patients, there were no significant changes in the proportion of NK or NKT-like cells or expression of granzyme A or NK cytotoxic potential versus controls. There were, however, increased expression of granzyme B, and decreased expression of CD94 by both cell types versus controls. The proportion of NK and NKTlike cells were increased in BALF in COPD, associated with increased NK cytotoxicity, increased expression of granzyme $\mathrm{B}$ and decreased expression of the inhibitory receptor CD94 by both cell types. This recent evidence supports the notion that treatment strategies that target NK and NKT-like cells, 
their cytotoxicity, and production of inflammatory mediators in the airway may improve COPD morbidity.

Numbers of CD4+ cells are raised in the airways and lungs of smokers with COPD. Two types of CD4+ cells accumulate in the lungs of stable COPD patients, Th1 and Th17 cells [82-84]. Th1 cells secrete more interferon $\gamma$, while Th17 cells regulate tissue inflammation by producing IL-17A and IL17F [85]. Th17 cytokines induce epithelial cells to produce antimicrobial peptides, chemokines, and granulocyte growth factors G-CSF and GM-CSF to promote neutrophil accumulation at the site of injury. Patients with COPD have increased numbers of IL-23 and IL-17 in bronchial epithelium.

On the contrary, smokers with COPD have significantly fewer T-regulatory cells (TREGs) in the lungs and lower levels of IL-10. TREGs are subsets of CD4+ cells with immunoregulatory functions. They inhibit autoimmunity and suppress inflammation. They also exert their suppressive effect on other $\mathrm{T}$ cells or on antigen presenting dendritic cells through the production of anti-inflammatory cytokines such as IL-10 and TGF $\beta[86]$.

4.2. B Cells. B cells are increased in large airways of COPD patients. Peribronchial lymphoid follicles are organised by lymphoid neogenesis [87] in T-cell and B-cell compartments through the lymphoid chemokines CCL19 and CCL21 and CXCL12 and CXCL13 [78, 88-90]. The B-cell-attracting chemokine CXCL13 is an important mediator in the formation of tertiary lymphoid organs. In a recent study of Litsiou et al. [89] lymphoid follicle formation in COPD may be driven by lung B cells via a CXCL13-dependent mechanism that involves Toll-like receptor and lymphotoxin receptor signaling. Cigarette smoke extract, $\mathrm{H}_{2} \mathrm{O}_{2}$, and LPS exposure upregulated B-cell-derived CXCL13. Notably, CXCL13 was required for efficient lung $\mathrm{B}$-cell migration toward COPD lung homogenates and induced lung B cells to upregulate lymphotoxin, which further promoted CXCL13 production, establishing a positive feedback loop. Most recently, Bracke et al. [90] showed that both mRNA and protein levels of CXCL13 were increased in lungs of CS-exposed mice and patients with COPD, and prophylactic and therapeutic administration of anti-CXCL13 antibodies completely prevented the CSinduced formation of pulmonary lymphoid follicles in mice. Interestingly, absence of tertiary lymphoid organs attenuated destruction of alveolar walls and inflammation in bronchoalveolar lavage (BAL) but did not affect airway wall remodelling.

Although new evidence about the follicular B cells is emerging, their pathogenic role in COPD is still controversial; it might be beneficial if protective against microbial colonization and infection or detrimental if directed against lung tissue antigens [76]. COPD has been regarded as an autoimmune disease, on the basis of the presence of B-cell lymphoid follicles in advanced COPD and the detection of several autoantibodies in the serum of patients with COPD $[13,91,92]$. There is a controversy in the literature concerning the role of antielastin antibodies. Antielastin antibody and Th1 responses in COPD patients were correlated with severity of emphysema [13]. However, Wood et al. [93], that only smoke exposure and not the disease state affected the antielastin antibody levels in serum. Furthermore, Greene et al. [92] reported no significant differences in the levels of antielastin autoantibodies in patients with COPD and in patients with $\alpha 1$-antitrypsin deficiency, compared to healthy controls. In line with these findings, most recently, Rinaldi et al. [94] showed no significant difference in antielastin antibody titres in patients with COPD compared with smoking controls. On the contrary, the titres were decreased significantly with increasing severity of COPD $(P<0.001)$. Antibodies against primary epithelial cells were recorded more frequently in COPD patients than controls and serum concentration of antitissue antibodies was correlated with the severity of airflow limitation [91]. Finally, antinuclear autoantibodies were more prevalent in COPD patients with lower body mass index than, healthy controls [95].

\section{Adaptive Immune Responses in Infection}

Infections of the respiratory tract contribute to the pathogenesis and course of COPD in at least two different ways: (i) viral and bacterial infections are the most important cause of acute COPD exacerbations and (ii) bacterial colonization and chronic infection of the airways amplify and perpetuate chronic inflammation in stable COPD [96]. Bacteria such as $H$. Influenza, S. pneumonia and Moraxella catarrhalis are detected in $25 \%$ of patients with stable COPD and more than $50 \%$ of patients during exacerbation [97] while a severe COPD exacerbation can be caused by. It is increasingly recognized that the human host is colonized by diverse, sitespecific microbial communities that constitute the human microbiome [98-100]. New evidence indicates that the composition of airway microbiota differs in states of health and disease and with severity of disease [101], or the use of inhaled corticosteroids and inhaled bronchodilators [102], and that the microbiota, as a collective entity, may contribute to pathophysiologic processes associated with chronic airway disease [101-106]. Using microarray analysis, airway specimens have been analyzed from COPD patients who were being managed for severe respiratory exacerbations [104]. Therefore, a diverse bacterial community is documented to be present during pulmonary exacerbation in the setting of antibiotic administration [105]. Viral infections are detected in $10-15 \%$ of sputum sample in stable COPD patients and in $30-60 \%$ of patients with COPD exacerbation (62) with rhinoviruses and influenza viruses being most frequently associated with the exacerbations [106].

Bacterial exacerbations lead to increased airway and systemic inflammation as a result of direct effects of bacteria and of the host response [96]. Several PAMPs of bacteria are recognised by specific PRRs on epithelial cells and innate immune cells, triggering the $\mathrm{NF} \kappa \mathrm{B}$ pathway and other signal transduction pathways resulting in the production of proinflammatory cytokines and chemokines [107]. Sputum and bronchoalveolar lavage analyses have shown increased concentrations of neutrophils, CXCL8, TNF- $\alpha$, and proteases, such as MMP-9 and neutrophil elastase in COPD patients with bacterial colonisation [96]. The colonization-induced triggering of PRR by microbial PAMPS amplifies the chronic neutrophilic airway inflammation in COPD. These adaptive 
immune responses contribute locally to the development of B-cell lymphoid follicles and mucosal IgA production, and systemically to the production of IgG antibodies in serum [108].

\section{Concluding Remarks}

In summary, accumulating evidence indicates that chronic inflammatory and immune responses play key roles in the development and progression of COPD. Data discussed in this review provides evidence for a role in the NLRP3 inflammasome in the airway inflammation observed in COPD.

Several molecular and cellular mediators of the innate and adaptive immune responses are regarded as therapeutic targets. A lot of research has to be done before possible new drugs for COPD encompassing modulators of TLRs, chemokine receptor antagonists, protease inhibitors, and anticytokine (e.g., anti-IL-17, anti-IL-18) targeted therapies are available.

\section{References}

[1] K. F. Rabe, S. Hurd, A. Anzueto et al., "Global strategy for the diagnosis, management, and prevention of chronic obstructive pulmonary disease: GOLD executive summary," The American Journal of Respiratory and Critical Care Medicine, vol. 176, no. 6, pp. 532-555, 2007.

[2] W. MacNee, "Pathogenesis of chronic obstructive pulmonary disease," Clinics in Chest Medicine, vol. 28, no. 3, pp. 479-513, 2007.

[3] R. A. Stockley, D. Mannino, and P. J. Barnes, "Burden and pathogenesis of chronic obstructive pulmonary disease," Proceedings of the American Thoracic Society, vol. 6, no. 6, pp. 524-526, 2009.

[4] P. W. Ind, "COPD disease progression and airway inflammation: uncoupled by smoking cessation," The European Respiratory Journal, vol. 26, no. 5, pp. 764-766, 2005.

[5] M. S. Simmons, J. E. Connett, M. A. Nides et al., "Smoking reduction and the rate of decline in FEV1: results from the Lung Health Study," The European Respiratory Journal, vol. 25, no. 6, pp. 1011-1017, 2005.

[6] K. F. Chung and I. M. Adcock, "Multifaceted mechanisms in COPD: inflammation, immunity, and tissue repair and destruction," The European Respiratory Journal, vol. 31, no. 6, pp. 13341356, 2008.

[7] A. Sharafkhaneh, N. A. Hanania, and V. Kim, "Pathogenesis of emphysema: from the bench to the bedside," Proceedings of the American Thoracic Society, vol. 5, no. 4, pp. 475-477, 2008.

[8] L. Taraseviciene-Stewart and N. F. Voelkel, "Molecular pathogenesis of emphysema," Journal of Clinical Investigation, vol. 118, no. 2, pp. 394-402, 2008.

[9] R. M. Tuder, T. Yoshida, W. Arap, R. Pasqualini, and I. Petrache, "Cellular and molecular mechanisms of alveolar destruction in emphysema: an evolutionary perspective," Proceedings of the American Thoracic Society, vol. 3, no. 6, pp. 503-510, 2006.

[10] G. T. Motz, B. L. Eppert, G. Sun et al., "Persistence of lung CD8 T cell oligoclonal expansions upon smoking cessation in a mouse model of cigarette smoke-induced emphysema," Journal of Immunology, vol. 181, no. 11, pp. 8036-8043, 2008.

[11] G. T. Motz, B. L. Eppert, S. C. Wesselkamper, J. L. Flury, and M. T. Borchers, "Chronic cigarette smoke exposure generates pathogenic $\mathrm{T}$ cells capable of driving COPD-like disease in
Rag2-/- mice," The American Journal of Respiratory and Critical Care Medicine, vol. 181, no. 11, pp. 1223-1233, 2010.

[12] A. K. Sullivan, P. L. Simonian, M. T. Falta et al., "Oligoclonal CD4+ T cells in the lungs of patients with severe emphysema," The American Journal of Respiratory and Critical Care Medicine, vol. 172, no. 5, pp. 590-596, 2005.

[13] S.-H. Lee, S. Goswami, A. Grudo et al., "Antielastin autoimmunity in tobacco smoking-induced emphysema," Nature Medicine, vol. 13, no. 5, pp. 567-569, 2007.

[14] P. J. Barnes, S. D. Shapiro, and R. A. Pauwels, "Chronic obstructive pulmonary disease: molecular and cellular mechanisms," The European Respiratory Journal, vol. 22, no. 4, pp. 672-688, 2003.

[15] S. Baraldo, G. Turato, C. Badin et al., "Neutrophilic infiltration within the airway smooth muscle in patients with COPD," Thorax, vol. 59, no. 4, pp. 308-312, 2004.

[16] D. M. Comer, J. C. Kidney, M. Ennis et al., "Airway epithelial cell apoptosis and inflammation in COPD, smokers and nonsmokers," The European Respiratory Journal, vol. 41, no. 54, pp. 1058-1067, 2013.

[17] M. Tanino, T. Betsuyaku, K. Takeyabu et al., "Increased levels of interleukin-8 in BAL fluid from smokers susceptible to pulmonary emphysema," Thorax, vol. 57, no. 5, pp. 405-411, 2002.

[18] D. Stǎnescu, A. Sanna, C. Veriter et al., "Airways obstruction, chronic expectoration, and rapid decline of FEV1 in smokers are associated with increased levels of sputum neutrophils," Thorax, vol. 51, no. 3, pp. 267-271, 1996.

[19] S. L. Traves, S. V. Culpitt, R. E. K. Russell, P. J. Barnes, and L. E. Donnelly, "Increased levels of the chemokines GRO $\alpha$ and MCP1 in sputum samples from patients with COPD," Thorax, vol. 57, no. 7, pp. 590-595, 2002.

[20] A. di Stefano, P. Maestrelli, A. Roggeri et al., "Upregulation of adhesion molecules in the bronchial mucosa of subjects with chronic obstructive bronchitis," The American Journal of Respiratory and Critical Care Medicine, vol. 149, no. 3, pp. 803810, 1994.

[21] S. D. Shapiro, "The macrophage in chronic obstructive pulmonary disease," The American Journal of Respiratory and Critical Care Medicine, vol. 160, no. 5, part 2, pp. S29-S32, 1999.

[22] R. Finkelstein, R. S. Fraser, H. Ghezzo, and M. G. Cosio, "Alveolar inflammation and its relation to emphysema in smokers," The American Journal of Respiratory and Critical Care Medicine, vol. 152, no. 5, pp. 1666-1672, 1995.

[23] A. di Stefano, A. Capelli, M. Lusuardi et al., "Severity of airflow limitation is associated with severity of airway inflammation in smokers," The American Journal of Respiratory and Critical Care Medicine, vol. 158, no. 4, pp. 1277-1285, 1998.

[24] A. Punturieri, S. Filippov, E. Allen et al., "Regulation of elastinolytic cysteine proteinase activity in normal and cathepsin K-deficient human macrophages," Journal of Experimental Medicine, vol. 192, no. 6, pp. 789-800, 2000.

[25] R. E. K. Russell, A. Thorley, S. V. Culpitt et al., "Alveolar macrophage-mediated elastolysis: roles of matrix metalloproteinases, cysteine, and serine proteases," The American Journal of Physiology_Lung Cellular and Molecular Physiology, vol. 283, no. 4, pp. L867-L873, 2002.

[26] A. di Stefano, G. Caramori, T. Oates et al., "Increased expression of nuclear factor- $\kappa \mathrm{B}$ in bronchial biopsies from smokers and patients with COPD," The European Respiratory Journal, vol. 20, no. 3, pp. 556-563, 2002. 
[27] G. Caramori, M. Romagnoli, P. Casolari et al., "Nuclear localisation of p65 in sputum macrophages but not in sputum neutrophils during COPD exacerbations," Thorax, vol. 58, no. 4, pp. 348-351, 2003.

[28] M. Saetta, M. Mariani, P. Panina-Bordignon et al., "Increased expression of the chemokine receptor CXCR3 and its ligand CXCL10 in peripheral airways of smokers with chronic obstructive pulmonary disease," The American Journal of Respiratory and Critical Care Medicine, vol. 165, no. 10, pp. 1404-1409, 2002.

[29] M. A. Birrell and S. Eltom, "The role of the NLRP3 Inflammasome in the pathogenesis of airway disease," Pharmacology and Therapeutics, vol. 130, no. 3, pp. 364-370, 2011.

[30] A. A. Wanderer, "Interleukin-1 $\beta$ targeted therapy in severe persistent asthma (SPA) and chronic obstructive pulmonary disease (COPD): proposed similarities between biphasic pathobiology of SPA/COPD and ischemia-reperfusion injury," Israel Medical Association Journal, vol. 10, no. 12, pp. 837-842, 2008.

[31] R. Zhou, A. S. Yazdi, P. Menu, and J. Tschopp, "A role for mitochondria in NLRP3 inflammasome activation," Nature, vol. 469, no. 7329, pp. 221-225, 2011.

[32] K. J. Ishii, S. Koyama, A. Nakagawa, C. Coban, and S. Akira, "Host innate immune receptors and beyond: making sense of microbial infections," Cell Host and Microbe, vol. 3, no. 6, pp. 352-363, 2008.

[33] B. Opitz, V. van Laak, J. Eitel, and N. Suttorp, "Innate immune recognition in infectious and noninfectious diseases of the lung," The American Journal of Respiratory and Critical Care Medicine, vol. 181, no. 12, pp. 1294-1309, 2010.

[34] L. Franchi, C. McDonald, T.-D. Kanneganti, A. Amer, and G. Núñez, "Nucleotide-binding oligomerization domain-like receptors: intracellular pattern recognition molecules for pathogen detection and host defense," Journal of Immunology, vol. 177, no. 6, pp. 3507-3513, 2006.

[35] T. Maes, K. R. Bracke, K. Y. Vermaelen et al., "Murine TLR4 is implicated in cigarette smoke-induced pulmonary inflammation," International Archives of Allergy and Immunology, vol. 141, no. 4, pp. 354-368, 2006.

[36] E. Doz, N. Noulin, E. Boichot et al., "Cigarette smoke-induced pulmonary inflammation is TLR4/MyD88 and IL-1R1/MyD88 signaling dependent," Journal of Immunology, vol. 180, no. 2, pp. 1169-1178, 2008.

[37] C. M. Freeman, F. J. Martinez, M. K. Han et al., "Lung CD8+ T cells inCOPD have increased expression of bacterial TLRs," Respiratory Research, vol. 1, no. 14, article 13, 2013.

[38] D. Perregaux and C. A. Gabel, "Interleukin- $1 \beta$ maturation and release in response to ATP and nigericin. Evidence that potassium depletion mediated by these agents is a necessary and common feature of their activity," Journal of Biological Chemistry, vol. 269, no. 21, pp. 15195-15203, 1994.

[39] Y. Qu, L. Franchi, G. Nunez, and G. R. Dubyak, "Nonclassical IL- $1 \beta$ secretion stimulated by $\mathrm{P} 2 \mathrm{X} 7$ receptors is dependent on inflammasome activation and correlated with exosome release in murine macrophages," Journal of Immunology, vol. 179, no. 3, pp. 1913-1925, 2007.

[40] S. Eltom, C. S. Stevenson, J. Rastrick et al., "P2x7 receptor and caspase 1 activation are central to airway inflammation observed after exposure to tobacco smoke," PLoS ONE, vol. 6, no. 9, Article ID e24097, 2011.

[41] S. Mariathasan and D. M. Monack, "Inflammasome adaptors and sensors: intracellular regulators of infection and inflammation," Nature Reviews Immunology, vol. 7, no. 1, pp. 31-40, 2007.
[42] F. S. Sutterwala, Y. Ogura, D. S. Zamboni, C. R. Roy, and R. A. Flavell, "NALP3: a key player in caspase-1 activation," Journal of Endotoxin Research, vol. 12, no. 4, pp. 251-256, 2006.

[43] E. R. Lazarowski, R. C. Boucher, and T. K. Harden, "Mechanisms of release of nucleotides and integration of their action as P2X- and P2Y-receptor activating molecules," Molecular Pharmacology, vol. 64, no. 4, pp. 785-795, 2003.

[44] S. C. Robson, E. Kaczmarek, J. B. Siegel et al., "Loss of ATP diphosphohydrolase activity with endothelial cell activation," Journal of Experimental Medicine, vol. 185, no. 1, pp. 153-163, 1997.

[45] A. Mohsenin and M. R. Blackburn, "Adenosine signaling in asthma and chronic obstructive pulmonary disease," Current Opinion in Pulmonary Medicine, vol. 12, no. 1, pp. 54-59, 2006.

[46] R. Polosa and M. R. Blackburn, "Adenosine receptors as targets for therapeutic intervention in asthma and chronic obstructive pulmonary disease," Trends in Pharmacological Sciences, vol. 30, no. 10 , pp. 528-535, 2009.

[47] M. Lommatzsch, S. Cicko, T. Müller et al., "Extracellular adenosine triphosphate and chronic obstructive pulmonary disease," The American Journal of Respiratory and Critical Care Medicine, vol. 181, no. 9, pp. 928-934, 2010.

[48] S. Cicko, M. Lucattelli, T. Müller et al., "Purinergic receptor inhibition prevents the development of smoke-induced lung injury and emphysema," Journal of Immunology, vol. 185, no. 1, pp. 688-697, 2010.

[49] E. Mortaz, S. Braber, M. Nazary, M. E. Givi, F. P. Nijkamp, and G. Folkerts, "ATP in the pathogenesis of lung emphysema," The European Journal of Pharmacology, vol. 619, no. 1-3, pp. 92-96, 2009.

[50] N. Ferhani, S. Letuve, A. Kozhich et al., "Expression of highmobility group box 1 and of receptor for advanced glycation end products in chronic obstructive pulmonary disease," The American Journal of Respiratory and Critical Care Medicine, vol. 181, no. 9, pp. 917-927, 2010.

[51] C. Hou, H. Zhao, L. Liu et al., "High mobility group protein B1 (HMGB1) in asthma: comparison of patients with chronic obstructive pulmonary disease and healthy controls," Molecular Medicine, vol. 17, no. 7-8, pp. 807-815, 2011.

[52] C. M. Wang, M. Jiang, and H. J. Wang, "Effect of NF- $\kappa$ B inhibitor on high-mobility group protein $\mathrm{B} 1$ expression in a COPD rat model," Medical Representative, vol. 7, no. 2, pp. 499502, 2013.

[53] S. Mitola, M. Belleri, C. Urbinati et al., "Cutting edge: extracellular high mobility group box-1 protein is a proangiogenic cytokine," Journal of Immunology, vol. 176, no. 1, pp. 12-15, 2006.

[54] M. B. Sukkar, L. G. Wood, M. Tooze et al., "Soluble RAGE is deficient in neutrophilic asthma and COPD," The European Respiratory Journal, vol. 39, no. 3, pp. 721-729, 2012.

[55] H. Kanazawa, Y. Tochino, K. Asai, Y. Ichimaru, T. Watanabe, and K. Hirata, "Validity of HMGB1 measurement in epithelial lining fluid in patients with COPD," The European Journal of Clinical Investigation, vol. 42, no. 4, pp. 419-426, 2012.

[56] T. L. Adair-Kirk, J. J. Atkinson, and R. M. Senior, "Smoke particulates stress lung cells," Nature Medicine, vol. 14, no. 10, pp. 1024-1025, 2008.

[57] A. Churg, S. Zhou, X. Wang, R. Wang, and J. L. Wright, "The role of lnterleukin-1 p in murine cigarette smoke-induced emphysema and small airway remodeling," The American Journal of Respiratory Cell and Molecular Biology, vol. 40, no. 4, pp. 482490, 2009. 
[58] M.-J. Kang, R. J. Homer, A. Gallo et al., "IL-18 is induced and IL18 receptor $\alpha$ plays a critical role in the pathogenesis of cigarette smoke-induced pulmonary emphysema and inflammation," Journal of Immunology, vol. 178, no. 3, pp. 1948-1959, 2007.

[59] E. C. Lucey, J. Keane, P.-P. Kuang, G. L. Snider, and R. H. Goldstein, "Severity of elastase-induced emphysema is decreased in tumor necrosis factor- $\alpha$ and interleukin- $1 \beta$ receptor-deficient mice," Laboratory Investigation, vol. 82, no. 1, pp. 79-85, 2002.

[60] S. Eltom, C. S. Stevenson, J. Rastrick et al., "The role of the inflammasome in cigarette smoke-induced inflammation," Proceedings of the British Pharmacological Socitey, vol. 8, p. 149, 2010.

[61] B. Singh, S. Arora, and V. Khanna, "Association of severity of COPD with IgE and interleukin-lbeta," Monaldi Archives for Chest Disease, vol. 73, no. 2, pp. 86-87, 2010.

[62] M. Singh, S.-H. Lee, P. Porter et al., "Human rhinovirus proteinase $2 \mathrm{~A}$ induces $\mathrm{TH} 1$ and $\mathrm{TH} 2$ immunity in patients with chronic obstructive pulmonary disease," Journal of Allergy and Clinical Immunology, vol. 125, no. 6, pp. 1369.e2-1378.e2, 2010.

[63] U. Lappalainen, J. A. Whitsett, S. E. Wert, J. W. Tichelaar, and K. Bry, "Interleukin- $1 \beta$ causes pulmonary inflammation, emphysema, and airway remodeling in the adult murine lung," The American Journal of Respiratory Cell and Molecular Biology, vol. 32, no. 4, pp. 311-318, 2005.

[64] F. M. Botelho, C. M. T. Bauer, D. Finch et al., "IL-1 $\alpha /$ IL-1R1 expression in chronic obstructive pulmonary disease and mechanistic relevance to smoke-induced neutrophilia in mice," PLoS ONE, vol. 6, no. 12, Article ID e28457, 2011.

[65] F. M. Botelho, J. K. Nikota, C. M. Bauer et al., "Cigarette smokeinduced accumulation of lung dendritic cells is interleukinlalpha-dependent in mice," Respiratory Research, vol. 13, article 81, 2012.

[66] N. S. Pauwels, K. R. Bracke, L. L. Dupont et al., "Role of IL-1 $\alpha$ and the Nlrp3/caspase-1/IL-1 $\beta$ axis in cigarette smoke-induced pulmonary inflammation and COPD," The European Respiratory Journal, vol. 38, no. 5, pp. 1019-1028, 2011.

[67] A. M. W. Petersen, M. Penkowa, M. Iversen et al., "Elevated levels of IL-18 in plasma and skeletal muscle in chronic obstructive pulmonary disease," Lung, vol. 185, no. 3, pp. 161-171, 2007.

[68] H. Imaoka, T. Hoshino, S. Takei et al., "Interleukin-18 production and pulmonary function in COPD," The European Respiratory Journal, vol. 31, no. 2, pp. 287-297, 2008.

[69] N. Rovina, E. Dima, C. Gerassimou, A. Kollintza, C. Gratziou, and C. Roussos, "Interleukin-18 in induced sputum: association with lung function in chronic obstructive pulmonary disease," Respiratory Medicine, vol. 103, no. 7, pp. 1056-1062, 2009.

[70] N. Rovina, E. Dima, C. Gerassimou, A. Kollintza, C. Gratziou, and C. Roussos, "IL-18 in induced sputum and airway hyperresponsiveness in mild asthmatics: effect of smoking," Respiratory Medicine, vol. 103, no. 12, pp. 1919-1925, 2009.

[71] J. Wang, X. Liu, M. Xie et al., "Increased expression of interleukin-18 and its receptor in peripheral blood of patients withchronic obstructive pulmonary disease," $C O P D$, vol. 9, no. 4, pp. 375-381, 2012.

[72] M. J. Kang, J. M. Choi, B. H. Kim et al., "IL-18 induces emphysema and airway and vascular remodeling via IFN- $\gamma$, IL-17A, and IL-13," The American Journal of Respiratory and Critical Care Medicine, vol. 185, no. 11, pp. 1205-1217, 2012.

[73] J. Wang, X. Liu, J. Xie et al., "Association of interleukin-18 promoter polymorphisms withchronic obstructive pulmonary disease in male smokers," International Journal of Immunogenetics, vol. 40, no. 3, pp. 204-208, 2013.
[74] A. Kratzer, J. Salys, C. Nold-Petry et al., "Role of IL-18 in secondhand smoke-induced emphysema," The American Journal of Respiratory Cell and Molecular Biology, vol. 48, no. 6, pp. 725732, 2013.

[75] T. Hoshino, S. Kato, N. Oka et al., "Pulmonary inflammation and emphysema: role of the cytokines IL-18 and IL-13," The American Journal of Respiratory and Critical Care Medicine, vol. 176, no. 1, pp. 49-62, 2007.

[76] M. G. Cosio, M. Saetta, and A. Agusti, "Immunologic aspects of chronic obstructive pulmonary disease," The New England Journal of Medicine, vol. 360, no. 23, pp. 2396-2454, 2009.

[77] M. Saetta, A. di Stefano, G. Turato et al., "CD8+ T-lymphocytes in peripheral airways of smokers with chronic obstructive pulmonary disease," The American Journal of Respiratory and Critical Care Medicine, vol. 157, no. 3, pp. 822-826, 1998.

[78] J. C. Hogg, F. Chu, S. Utokaparch et al., "The nature of smallairway obstruction in chronic obstructive pulmonary disease," The New England Journal of Medicine, vol. 350, no. 26, pp. 26452653, 2004.

[79] A. Proklou, N. Soulitzis, E. Neofytou et al., "Granule cytotoxic activity and oxidative DNA damage in smoking and non-smoking asthmatics," Chest, 2013.

[80] W. D. Kim, H. S. Chi, K. H. Choe et al., "A possible role for $\mathrm{CD} 8+$ and non-CD8+ cell granzyme B in early small airway wall remodelling in centrilobular emphysema," Respirology, vol. 18, no. 4, pp. 688-696, 2013.

[81] G. Hodge, M. Holmes, H. Jersmann et al., "The drug efflux pump Pgp1 in pro-inflammatory lymphocytes is a target for novel treatment strategies in COPD," Respiratory Research, vol. 14, article 63, 2013.

[82] R. A. Urbanowicz, J. R. Lamb, I. Todd, J. M. Corne, and L. C. Fairclough, "Enhanced effector function of cytotoxic cells in the induced sputum of COPD patients," Respiratory Research, vol. 11, article 76, 2010.

[83] A. di Stefano, G. Caramori, I. Gnemmi et al., "T helper type 17related cytokine expression is increased in the bronchial mucosa of stable chronic obstructive pulmonary disease patients," Clinical and Experimental Immunology, vol. 157, no. 2, pp. 316324, 2009.

[84] S. Grumelli, D. B. Corry, L.-Z. Song et al., "An immune basis for lung parenchymal destruction in chronic obstructive pulmonary disease and emphysema," PLoS Medicine, vol. 1, no. 1, article e8, 2004.

[85] P. Miossec, T. Korn, and V. K. Kuchroo, "Interleukin-17 and type 17 helper T cells," The New England Journal of Medicine, vol. 361, no. 9, pp. 848-898, 2009.

[86] Q. Tang and J. A. Bluestone, “The Foxp3+ regulatory T cell: a jack of all trades, master of regulation," Nature Immunology, vol. 9, no. 3, pp. 239-244, 2008.

[87] G. G. Brusselle, T. Demoor, K. R. Bracke, C.-A. Brandsma, and W. Timens, "Lymphoid follicles in (very) severe COPD: beneficial or harmful?" The European Respiratory Journal, vol. 34, no. 1, pp. 219-230, 2009.

[88] B. W. A. van der Strate, D. S. Postma, C.-A. Brandsma et al., "Cigarette smoke-induced emphysema: a role for the B cell?" The American Journal of Respiratory and Critical Care Medicine, vol. 173, no. 7, pp. 751-758, 2006.

[89] E. Litsiou, M. Semitekolou, I. E. Galani et al., "CXCL13 production in B cells via Toll-like receptor/lymphotoxin receptor signaling is involved in lymphoid neogenesis in chronic obstructive pulmonary disease," The American Journal of Respiratory and Critical Care Medicine, vol. 187, no. 11, pp. 1194-1202, 2013. 
90] K. R. Bracke, F. M. Verhamme, L. J. Seys et al., "Role of CXCL13 in cigarettesmoke-induced lymphoid follicle formation and COPD," American Journal of Respiratory and Critical Care Medicine. In press.

[91] B. Nunez, J. Sauleda, J. M. Anto et al., "Anti-tissue antibodies are related to lung function in chronic obstructive pulmonary disease," The American Journal of Respiratory and Critical Care Medicine, vol. 183, no. 8, pp. 1025-1031, 2011.

[92] C. M. Greene, T. B. Low, S. J. O’Neill, and N. G. McElvaney, "Anti-proline-glycine-proline or antielastin autoantibodies are not evident in chronic inflammatory lung disease," The American Journal of Respiratory and Critical Care Medicine, vol. 181, no. 1, pp. 31-35, 2010.

[93] A. M. Wood, P. de Pablo, C. D. Buckley, A. Ahmad, and R. A. Stockley, "Smoke exposure as a determinant of autoantibody titre in $\alpha 1$-antitrypsin deficiency and COPD," The European Respiratory Journal, vol. 37, no. 1, pp. 32-38, 2011.

[94] M. Rinaldi, A. Lehouck, N. Heulens et al., "Antielastin B-cell and T-cell immunity in patients with chronic obstructive pulmonary disease," Thorax, vol. 67, no. 8, pp. 694-700, 2012.

[95] H. P. J. Bonarius, C. A. Brandsma, H. A. M. Kerstjens et al., "Antinuclear autoantibodies are more prevalent in COPD in association with low body mass index but not with smoking history," Thorax, vol. 66, no. 2, pp. 101-107, 2011.

[96] S. Sethi and T. F. Murphy, "Infection in the pathogenesis and course of chronic obstructive pulmonary disease," The New England Journal of Medicine, vol. 359, no. 22, pp. 2355-2365, 2008.

[97] A. Rossel, E. Monso, N. Soler et al., "Microbiologic determinants of exacerbation in chronic obstructive pulmonary disease," Archives of Internal Medicine, vol. 165, no. 8, pp. 891-897, 2005.

[98] L. Dethlefsen, M. McFall-Ngai, and D. A. Relman, "An ecological and evolutionary perspective on humang-microbe mutualism and disease," Nature, vol. 449, no. 7164, pp. 811-818, 2007.

[99] E. S. Charlson, K. Bittinger, A. R. Haas et al., “Topographical continuity of bacterial populations in the healthy human respiratory tract," The American Journal of Respiratory and Critical Care Medicine, vol. 184, no. 8, pp. 957-963, 2011.

[100] E. S. Charlson, K. Bittinger, J. Chen et al., "Assessing bacterial populations in the lung by replicate analysis of samples from the upper and lower respiratory tracts," PLoS One, vol. 7, no. 9, Article ID e42786, 2012.

[101] M. A. Sze, P. A. Dimitriu, S. Hayashi et al., "The lung tissue microbiome inchronic obstructive pulmonary disease," The American Journal of Respiratory and Critical Care Medicine, vol. 185, no. 10, pp. 1073-1080, 2012.

[102] A. A. Pragman, H. B. Kim, C. S. Reilly et al., "The lung microbiome in moderate and severechronic obstructive pulmonary disease," PLoS One, vol. 7, no. 10, Article ID e47305, 2012.

[103] M. K. Han, Y. J. Huang, J. J. LiPuma et al., "Significance of the microbiome in obstructive lung disease," Thorax, vol. 67, no. 5, pp. 456-463, 2012.

[104] J. R. Erb-Downward, D. L. Thompson, M. K. Han et al., "Analysis of the lung microbiome in the "Healthy" smoker and in COPD," PLoS One, vol. 6, no. 2, Article ID e16384, 2011.

[105] Y. J. Huang and S. V. Lynch, "The emerging relationship between the airway microbiota and chronic respiratory disease: clinical implications," Expert Review of Respiratory Medicine, vol. 5, no. 6, pp. 809-821, 2011.
[106] P. Mallia, S. D. Message, V. Gielen et al., "Experimental rhinovirus infection as a human model of chronic obstructive pulmonary disease exacerbation," The American Journal of Respiratory and Critical Care Medicine, vol. 183, no. 6, pp. 734742, 2011.

[107] B. Levine, N. Mizushima, and H. W. Virgin, "Autophagy in immunity and inflammation," Nature, vol. 469, no. 7330, pp. 323-335, 2011.

[108] C. A. Feghali-Bostwick, A. S. Gadgil, L. E. Otterbein et al., "Autoantibodies in patients with chronic obstructive pulmonary disease," The American Journal of Respiratory and Critical Care Medicine, vol. 177, no. 2, pp. 156-163, 2008. 


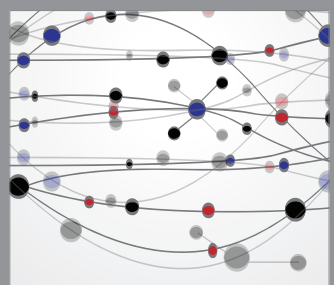

The Scientific World Journal
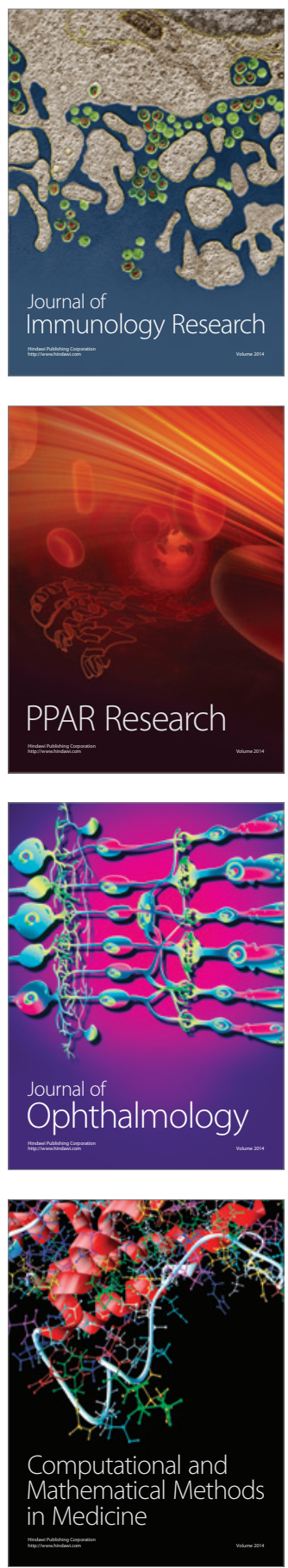

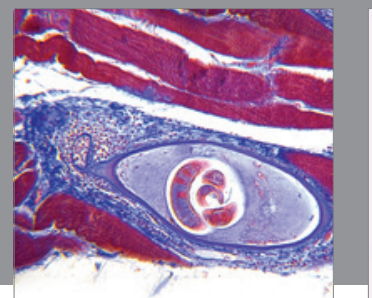

Gastroenterology

Research and Practice
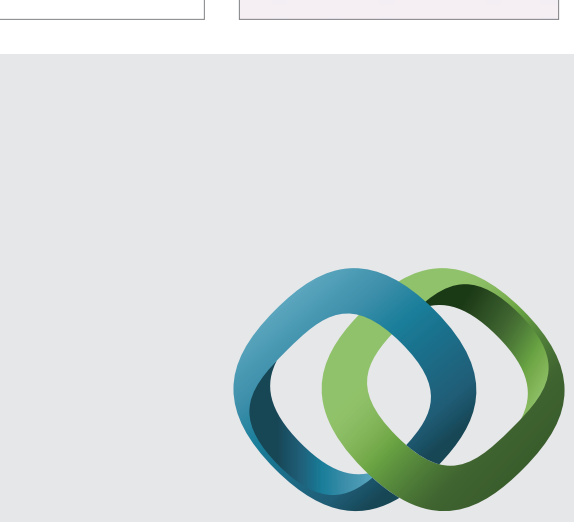

\section{Hindawi}

Submit your manuscripts at

http://www.hindawi.com
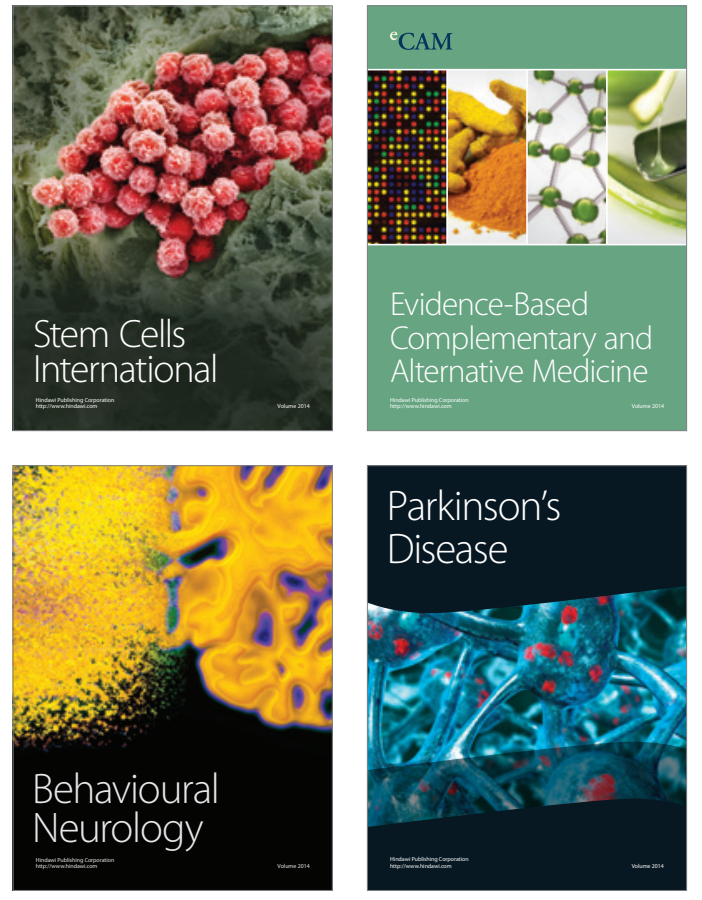
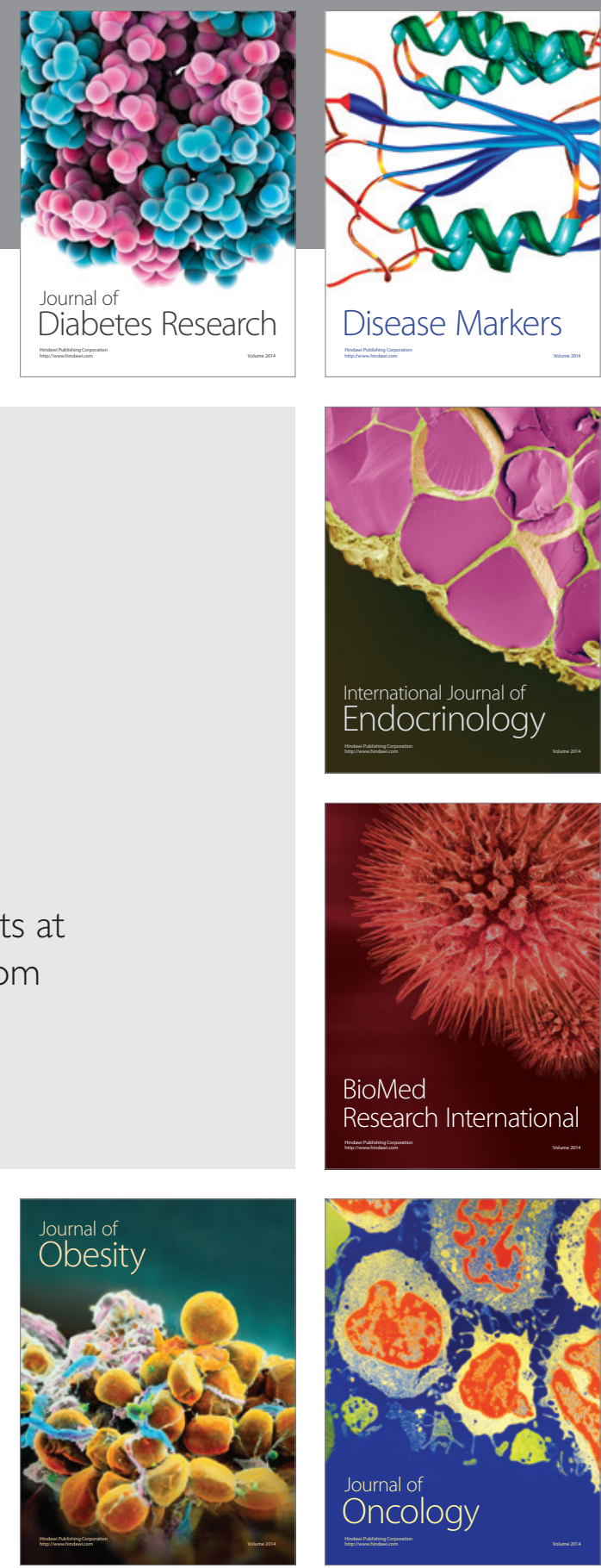

Disease Markers
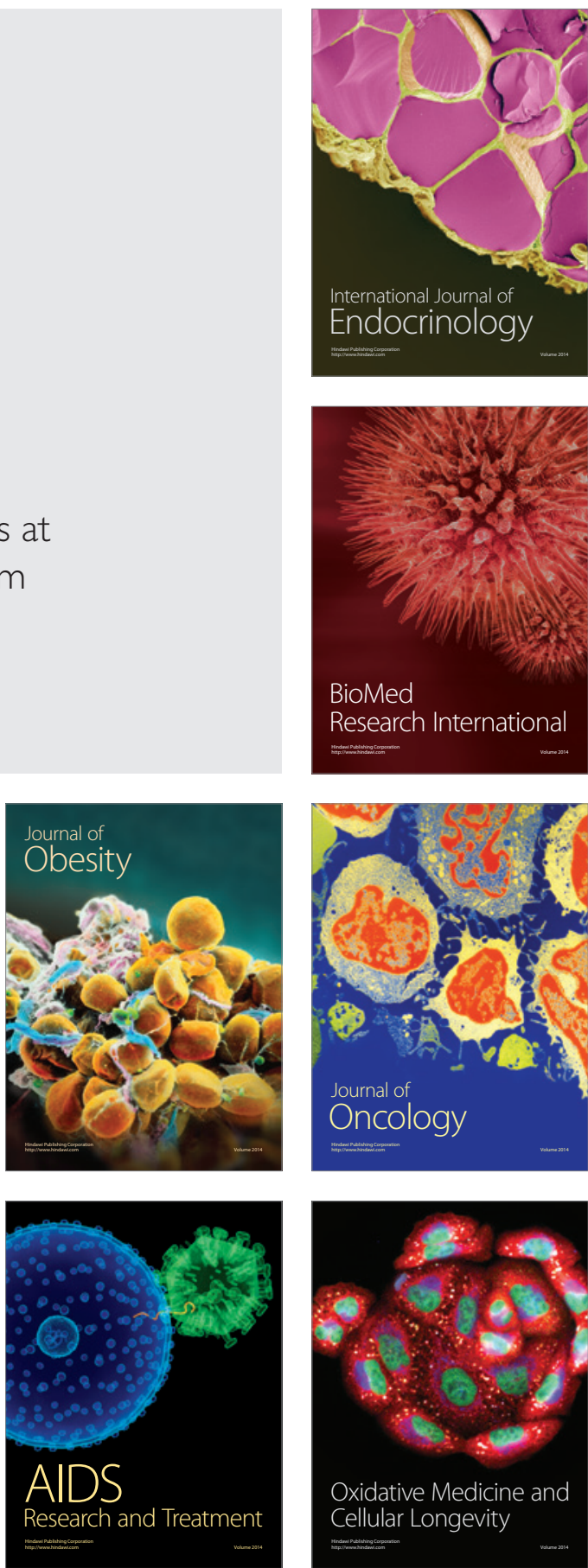